\title{
Public Investment in Basic Education and Economic Growth*
}

\author{
Vladimir Kühl Teles ${ }^{\dagger}$ \\ Universidade de Brasília \\ Departamento de Economia \\ vkteles@unb.br \\ Joaquim P. Andrade \\ Universidade de Brasília \\ Departamento de Economia \\ jandrade@unb.br
}

19th July 2004

\begin{abstract}
The main objective of this paper was to visualize the relation between government spending on basic education and the human capital accumulation process, observing the impacts of this spending on individual investments in higher education, and on economic growth. From the results obtained, we may reach the central conclusion that basic education affects agents' decisions over their lifetime, and that the significance of the relation between public spending on education and economic growth is altered by changes in the composition of government spending with regard to basic and higher education, and this relation may be insignificant when higher education is not promoted.
\end{abstract}

\footnotetext{
${ }^{*}$ We would like to thank Adolfo Sachsida, Jorge Arbache, Bernardo Müller and Samuel Pessoa for valuable comments and insights. The usual disclaimer applies.

${ }^{\dagger}$ Universidade de Brasília, Instituto de Ciências Humanas, Departamento de Economia, Caixa postal 04302, Campus Universitário Darcy Ribeiro - ICC Ala Norte Brasília-DF, Brazil, CEP:70919-970, Tel:(55)(61) 307-2498 Fax: (55)(61) 340-2311
} 


\section{Introduction}

The understanding of the differences in economic growth trends among countries is the main objective of endogenous growth models. Ever since the seminal article published by Lucas (1988), this theory has emphasized that differences in human capital accumulation among countries is a key factor in explaining their differences in growth. It then became necessary to understand the human capital accumulation process, and consequently, the reasons why countries' do not converge towards the same level of human capital. This study aims at contributing towards this debate by constructing five complementary theoretical models addressing the relation between government spending on basic education and the accumulation of human capital, and consequently economic growth.

Since the government is directly responsible for the majority of the investments in basic education in most countries, it is possible to relate the accumulation of human capital to government spending. In this sense, several articles have constructed theoretical models relating government spending on education to economic growth, in which government investment in education has a direct effect upon the accumulation of human capital, and consequently on long run growth. Included here are articles by Glomm and Ravikumar (1992, 1997, 1998), Eckstein and Zilcha (1994), Kaganovich and Zilcha (1999), Cassou and Lansing (2001), Blankeanu (2003) and Blankenau and Simpson (2004). At the same time, other articles have pointed out the indirect relation between government spending on education and the accumulation of human capital through private sector subsidies as, for example, in Zhang (1996), Milesi-Ferretti and Roubini (1998), Hendricks (1999), Brauninger and Vidal (1999) and Bouzahzah et. al. (2002).

However, the empirical evidence regarding the relation between government spending on education and growth is not consensual. Cullison (1993) and Barro and Salai-Martin (1999) found a positive relation between government spending on education and growth, while Zhang and Casagrande (1998) determined that the subsidizing of education incremented economic growth in developing as well as developed countries. Easterly and Rebelo (1993) also found such a relation, but for only certain specifications, while Levine and Renelt (1992) concluded that government spending on public education is not robustly correlated with rates of growth.

Thus, it may be argued that although the theoretical models constructed for this relation are correct regarding the direction of the relation, it is possible that some aspect of this relation has not been considered, as verified by the asymmetry of the empirical evidence.

This study seeks to put forth the notion that the effect of government spending on education is not the same for any given type of government spending on education, in an attempt to provide theoretical answers to the empirical difficulties evidenced by this relation.

Toward this end, using UNESCO data between 1999 and 2001, we observed that in countries with high per-capita GNP, a lower proportion of overall government out- 
lays for education is spent on basic education, as compared to countries with lower per capita GNP. For example, the United States, United Kingdom and Japan respectively spent $31.4 \%, 24.4 \%$, and $35 \%$ of their overall outlays for education on primary education, while Chad, Bangladesh, Lesoto and Niger respectively spent 57.5\%, 38.1\%, $48.6 \%$ and $49.3 \%$ ( $\mathrm{Su}, 2004)$. Although this evidence is not conclusive, it poses a question: is the composition of government spending on education important with regard to its significance in determining long run growth?

The fundamental goal of this study was to visualize the relation between government spending on basic education and the human capital accumulation process, observing the impacts of this spending on individual investments in higher education, and on economic growth.

This chapter is divided into an additional five sections. In the following section, we consider the basic model to be discussed; in section three the government is introduced in the basic model, and in section four three non-linear models are formalized. In section five, the relation between government spending on basic education and economic growth is discussed, based on the five models developed. Lastly, in section six, we put forth our concluding remarks.

\section{The Basic Model}

In this section, the simplest model possible was designed in order to provide a clearer view of its main characteristics. A overlapping generation model was designed, in which the agents have two periods in their lives: one beginning the moment the agent reaches the age of entering the labor market, having to allocate all his or her time between working or increasing his or her human capital stock, and a second period in which the agent only works. The agent's consumption in each of these periods is determined by the following equations:

$$
\begin{gathered}
c_{t}=\left(1-h_{t}\right) H_{t} \\
c_{t+1}=H_{t+1}
\end{gathered}
$$

where, $c$ is the agent's consumption, $h$ is the number of hours dedicated to the accumulation of human capital, and $H$ is the agent's human capital stock. It must be pointed out that in period $t$ the agent is endowed with an initial human capital stock $H_{t}$ which is exogenous, which was accumulated prior to the period in which the agent reaches the age of entering the labor market. Thus, following Su (2004), it may be considered that the agent's final human capital stock shall be an additive function of the hours spent in accumulating human capital in higher education and the human capital stock accumulated in the initial period. Therefore, the human capital stock in period $t+1$ is given by, 


$$
H_{t+1}=h_{t}+H_{t}
$$

In this model, the entire product is consumed by the agent, and the production function is given solely by multiplying the number of hours worked by his or her human capital stock. Since in the second period the agent only works, his or her production is equal to the human capital stock times one.

Thus, the agent shall choose the number of hours that he or she will allocate between work and the accumulation of human capital in the first period in order to maximize his or her intertemporal utility function. In other words, assuming CRRA, he or she must solve the following maximization problem,

$$
\max _{h}\left(\frac{c_{t}^{1-\theta}-1}{1-\theta}\right)+\beta\left(\frac{c_{t+1}^{1-\theta}-1}{1-\theta}\right)
$$

where $\theta \in \Re_{+}$is the risk aversion coefficient, and $\beta \in(0,1)$ is the temporal discount rate. Hence, by substituting (3) in (2), and then (1) and (2) in (4), the consumer's maximization problem then becomes,

$$
\max _{h}\left(\frac{[(1-h) H]^{1-\theta}-1}{1-\theta}\right)+\beta\left(\frac{(h+H)^{1-\theta}-1}{1-\theta}\right)
$$

where $H \equiv H_{t}$ since $H_{t+1}$ no longer appears, and $h \equiv h_{t}$.

Solving this problem, we obtain the following first order condition,

$$
[(1-h) H]^{-\theta}(-H)+\beta(h+H)^{-\theta}=0
$$

By performing algebraic manipulations in order to isolate $h$, obtained the agent's optimal choice of $h$, which is given by,

$$
h=\frac{\beta^{\left(\frac{1}{\theta}\right)} H^{\left(\frac{\theta-1}{\theta}\right)}-H}{1+\beta^{\left(\frac{1}{\theta}\right)} H^{\left(\frac{\theta-1}{\theta}\right)}}
$$

From this equation, it is possible to obtain the result used in proposition 1.

Proposition 1 The number of hours dedicated to the accumulation of human capital, $h$, is related to the agent's initial human capital stock, $H$. In particular, when $\theta$ is less than 1, this relation is positive.

Proof: In order to prove this, a sign analysis is performed for $\partial h / \partial H$ from (7), which leads to,

$$
\frac{\partial h}{\partial H}=\frac{\left[\beta^{\frac{1}{\theta}}\left(\frac{\theta-1}{\theta}\right) H^{\left(-\frac{1}{\theta}\right)}-1\right]\left[1+\beta^{\frac{1}{\theta}} H^{\left(\frac{\theta-1}{\theta}\right)}\right]-\left[\beta^{\frac{1}{\theta}} H^{\left(\frac{\theta-1}{\theta}\right)}-H\right]\left[\beta^{\frac{1}{\theta}}\left(\frac{\theta-1}{\theta}\right) H^{\left(-\frac{1}{\theta}\right)}\right]}{\left[1+\beta^{\frac{1}{\theta}} H^{\left(\frac{\theta-1}{\theta}\right)}\right]}
$$


Hence, $\partial h / \partial H>0$ if,

$$
\left[\beta^{\frac{1}{\theta}}\left(\frac{\theta-1}{\theta}\right) H^{\left(-\frac{1}{\theta}\right)}-1\right]\left[1+\beta^{\frac{1}{\theta}} H^{\left(\frac{\theta-1}{\theta}\right)}\right]>\left[\beta^{\frac{1}{\theta}} H^{\left(\frac{\theta-1}{\theta}\right)}-H\right]\left[\beta^{\frac{1}{\theta}}\left(\frac{\theta-1}{\theta}\right) H^{\left(-\frac{1}{\theta}\right)}\right]
$$

meaning if,

$$
\frac{\left[\beta^{\frac{1}{\theta}}\left(\frac{\theta-1}{\theta}\right) H^{\left(-\frac{1}{\theta}\right)}-1\right]}{\left[\beta^{\frac{1}{\theta}}\left(\frac{\theta-1}{\theta}\right) H^{\left(-\frac{1}{\theta}\right)}\right]}>\frac{\left[\beta^{\frac{1}{\theta}} H^{\left(\frac{\theta-1}{\theta}\right)}-H\right]}{\left[1+\beta^{\frac{1}{\theta}} H^{\left(\frac{\theta-1}{\theta}\right)}\right]}
$$

or, in other words,

$$
1-X>Y-Z
$$

where, $X=\frac{1}{\left[\beta^{\frac{1}{\theta}}\left(\frac{\theta-1}{\theta}\right) H\left(-\frac{1}{\theta}\right)\right]}$

$$
Y=\frac{\left[\beta^{\frac{1}{\theta}} H^{\left(\frac{\theta-1}{\theta}\right)}\right]}{\left[1+\beta^{\frac{1}{\theta}} H\left(\frac{\theta-1}{\theta}\right)\right]}
$$

and

$$
Z=\frac{H}{\left[1+\beta^{\frac{1}{\theta}} H\left(\frac{\theta-1}{\theta}\right)\right]}
$$

Thus, if $\theta<1$, then $X<0$, and consequently, $1-X>1$. At the same time, it is evident that $Y<1$, and that $Z>0$, implying that $Y-Z<1$. Therefore, $1-X>Y-Z$, implying that $\partial h / \partial H>0$.

Proposition 1 is of vital importance by making it clear that investments made during an individual's childhood affect the economic decisions that this individual will make in adulthood. Specifically with regard to the accumulation of human capital, we have that the more human capital an individual accumulates during childhood, the more time this individual will allocate towards accumulating human capital in adulthood. This proposition thus puts forth that the most important government education spending would be that directed towards basic education, since agents' would be directly stimulated to accumulate human capital in adulthood for having reached adulthood with a high human capital stock.

We could now ask ourselves how this result would be affected if we were to include government that invests in basic education, but that also taxes adults, or furthermore, 
observe the changes brought about by these results if non-linearities, such as decreasing returns to human capital in the production function, or hours spent by individuals in accumulating human capital were introduced in the model. These aspects will be dealt with in the following sections.

\section{The Model with Government}

In the previous section, we saw that the human capital stock accumulated by "school age" agents points to an increase in the number of hours spent on human capital accumulation as adults. Thus, since the public sector is primarily responsible for the agents' basic education, we may consider that the human capital stock obtained by the agents during school age is a function of government spending on basic education with regard to GNP. We then have that,

$$
H=\varphi \varepsilon
$$

where $\varepsilon \in(0,1)$ represents the government spending on education/GNP ratio, and $\varphi>0$ is a constant that represents the marginal productivity of government spending with regard to the human capital stock. Thus, the agent's consumption in each period shall be given by,

$$
\begin{aligned}
& c_{t}=[(1-h) \varphi \varepsilon](1-\varepsilon) \\
& c_{t+1}=[\varphi \varepsilon+h](1-\varepsilon)
\end{aligned}
$$

It must be pointed out that basic education spending is financed by revenue collected in previous generations. Hence, agents will be confronted by an intertemporal trade-off between human capital accumulation and taxation. From these equations, the agent's maximization problem then becomes,

$$
\max _{h}\left\{\frac{\{[(1-h) \varphi \varepsilon](1-\varepsilon)\}^{1-\theta}-1}{1-\theta}\right\}+\beta\left\{\frac{[(\varphi \varepsilon+h)(1-\varepsilon)]^{1-\theta}-1}{1-\theta}\right\}
$$

Solving this equation, the following first order condition is determined,

$$
\left[\frac{(\varphi \varepsilon+h)}{(1-h) \varphi \varepsilon}\right]^{\theta}=\frac{\beta}{\varphi \varepsilon}
$$

Then, rearranging the terms in order to isolate $h$, we obtain,

$$
h=\frac{\left(\frac{\beta}{\varphi \varepsilon}\right)^{\frac{1}{\theta}} \varphi \varepsilon-\varphi \varepsilon}{1+\left(\frac{\beta}{\varphi \varepsilon}\right)^{\frac{1}{\theta}} \varphi \varepsilon}
$$

From this result, we may then move on to Proposition 2. 
Proposition 2 The number of hours spent on accumulating human capital, $h$, is related to the amount of government spending on basic education, $\varepsilon$. A sign cannot be determined for this relation, for it varies according to the preference parameters of the agents.

Proof: To prove this proposition, a sign analysis is performed on $\partial h / \partial \varepsilon$, from (17) which is given by,

$$
\frac{\partial h}{\partial \varepsilon}=\frac{[\Omega-\varphi][1+X]-[\Omega(X-\varphi \varepsilon)]}{[1+X]^{2}}
$$

where,

$$
X=\beta^{\frac{1}{\theta}}(\varphi \varepsilon)^{\frac{\theta-1}{\theta}}
$$

and

$$
\Omega=\left(\frac{\theta-1}{\theta}\right) \beta^{\frac{1}{\theta}} \varphi^{\frac{\theta-1}{\theta}} \varepsilon^{\frac{-1}{\theta}}
$$

The sign of this relation critically depends on the model's parameter values, as shown in figure 1.

\section{Non-Linear Models}

The results obtained in the sections above were constructed considering a perfect case of linearity, entailing effects of scale with regard to human capital, investment in human capital, and government spending. However, said functional forms are not a consensus. Jones (1995), for example, developed several arguments against this type of linearity, and demonstrates that results varied drastically when decreasing returns were considered. We shall now introduce three types of decreasing returns individually, and observe their effects on the results of the models.

\subsection{Decreasing Returns to Human Capital Stock}

We shall initially consider the possibility of human capital having decreasing returns in the production function. Consequently, the agent's consumption in the two periods is given by,

$$
c_{t}=\left[(1-h)(\varphi \varepsilon)^{\alpha}\right](1-\varepsilon)
$$


Figure 1:
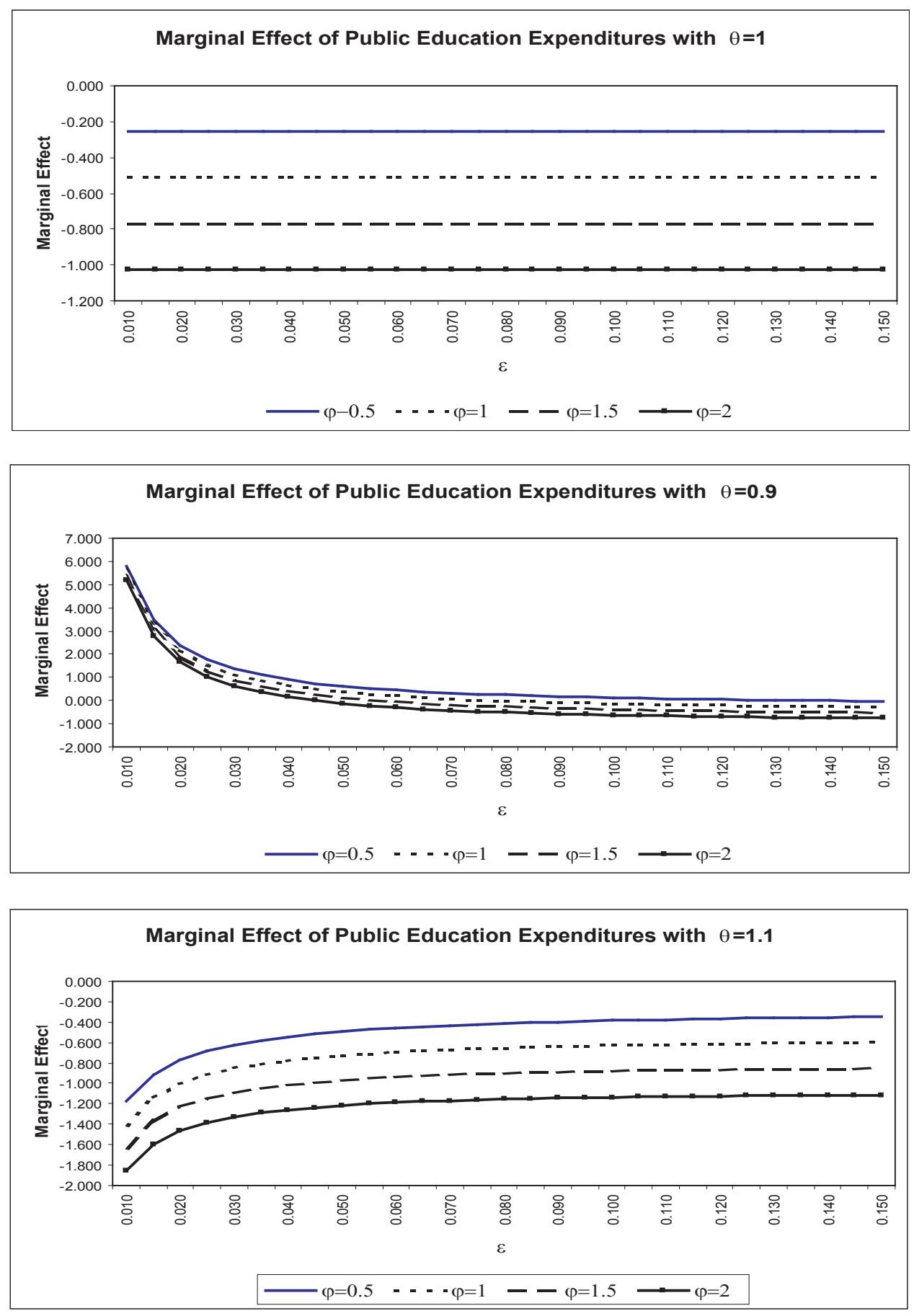


$$
c_{t+1}=[\varphi \varepsilon+h]^{\alpha}(1-\varepsilon)
$$

where $\alpha \in(0,1)$ provides the value of the decreasing returns to education in production. From these equations, the agent's maximization problem is given by,

$$
\max _{h} \frac{\left\{\left[(1-h)(\varphi \varepsilon)^{\alpha}\right](1-\varepsilon)\right\}^{1-\theta}-1}{1-\theta}+\beta \frac{\left\{(\varphi \varepsilon+h)^{\alpha}(1-\varepsilon)\right\}^{1-\theta}-1}{1-\theta}
$$

By solving this maximization problem, we reach the following first order condition,

$$
\left[\frac{(\varphi \varepsilon+h)^{\alpha}}{(1-h)(\varphi \varepsilon)^{\alpha}}\right]=\frac{\beta \alpha h^{\alpha-1}}{(\varphi \varepsilon)^{\alpha}}
$$

Thus, from this relation, we may formulate proposition 3 .

Proposition 3 The number of hours spent on the accumulation of human capital, $h$, is related to the amount of government spending on basic education, $\varepsilon$. In particular, said relation is negative if $\theta \alpha<1$.

Proof: In order to prove this proposition, we must apply the implicit function theorem to equation (22), thus obtaining,

$$
\frac{d h}{d \varepsilon}=\frac{\left[(1-h)(\beta \alpha)^{\frac{1}{\theta}} \varphi\left(\frac{\theta \alpha-1}{\theta}\right) \varepsilon^{\left(\frac{\theta \alpha-1-\theta}{\theta}\right)}-h^{\left(\frac{1-\alpha}{\theta}\right)} \alpha(\varphi \varepsilon+h)^{\alpha-1} \varphi\right]}{\left[h^{\frac{1-\alpha}{\theta}} \alpha(\varphi \varepsilon+h)^{\alpha-1}+\varphi(\varepsilon+h)^{\alpha}\left(\frac{1-\alpha}{\theta}\right) h^{\left(\frac{-\alpha}{\theta}\right)}+(\beta \alpha)^{\frac{1}{\theta}} \varphi \varepsilon^{\left(\frac{\theta \alpha-1}{\theta}\right)}\right]}
$$

From the above equation, it becomes clear that $d h / d \varepsilon$ is negative when $\theta \alpha<1$, although the sign of this relation may not be determined when $\theta \alpha>1$

Proposition 3 greatly influences the orientation of government education policy since it becomes clear that, in the presence of decreasing returns to human capital, agents would not necessarily be motivated to accumulate human capital with increases in government spending on basic education. It must be noted that since $\theta<1$, which is usually the case in calibration problems, this relation is negative, meaning that the government would be inclined to subsidize higher education in order to make it attractive to the economic agents.

\subsection{Decreasing Returns to Human Capital Accumulation}

Let us now consider the possibility of the agent being confronted with decreasing returns to human capital accumulation; in other words, the marginal return to the number 
of hours spent accumulating human capital is decreasing since more hours are spent on this activity. In this case, the agent's consumption in each time period is given by,

$$
\begin{gathered}
c_{t}=(1-h) \varphi \varepsilon(1-\varepsilon) \\
c_{t+1}=\left(\varphi \varepsilon+h^{\gamma}\right)(1-\varepsilon)
\end{gathered}
$$

where $\gamma$ represents the decreasing returns to human capital accumulation. Hence, the agent's intertemporal utility maximizing problem is given by,

$$
\max _{h}\left\{\frac{[(1-h) \varphi \varepsilon(1-\varepsilon)]^{1-\theta}-1}{1-\theta}\right\}+\beta\left\{\frac{\left[\left(\varphi \varepsilon+h^{\gamma}\right)(1-\varepsilon)\right]^{1-\theta}-1}{1-\theta}\right\}
$$

This problem's first order condition is thus given by,

$$
\left[\frac{\varphi \varepsilon+h^{\gamma}}{(1-h) \varphi \varepsilon}\right]^{\theta}=\frac{\beta \gamma h^{\gamma-1}}{\varphi \varepsilon}
$$

From this relation, we may then move on to the result put forth in proposition 4 .

Proposition 4 The number of hours expended on the accumulation of human capital, $h$, is related to the amount of government spending on basic education, $\varepsilon$, and, in particular, this relation is negative if $\theta<1$.

Proof: In order to prove the above proposition, we must apply the implicit function theorem to equation (27), thus obtaining,

$$
\frac{d h}{d \varepsilon}=\frac{\left(\frac{\theta-1}{\theta}\right)\left[(\beta \gamma)^{\frac{1}{\theta}} \varphi^{\frac{\theta-1}{\theta}} h^{\frac{\gamma-1}{\theta}}(1-h)\right] \varepsilon^{\frac{-1}{\theta}}-\gamma}{\gamma h^{\gamma-1}-\left[(\beta \gamma)^{\frac{1}{\theta}}(\varphi \varepsilon)^{\frac{\theta-1}{\theta}}\right]\left[\frac{(\gamma-1)(1-h)-\theta h}{\theta h}\right] h^{\gamma-1}}
$$

From the above equation, it becomes clear that $d h / d \varepsilon$ is negative when $\theta<1$, although the sign of this relation may not be determined when $\theta>1$.

Thus, as in the previous subsection, we have that the agents would not necessarily be stimulated to accumulate human capital with increases in government spending on basic education. Hence, in the presence of decreasing returns, either regarding human capital, or human capital accumulation, the government would have to subsidize higher education in order to make it attractive to economic agents. 


\subsection{Decreasing Returns to Government Spending on Education}

Lastly, we shall observe the possible effects that decreasing returns to government spending on education have on the accumulation of human capital. In this case, the agent's consumption functions are given by,

$$
\begin{aligned}
& c_{t}=(1-h) \varphi \varepsilon^{\phi}(1-\varepsilon) \\
& c_{t+1}=\left[\varphi \varepsilon^{\phi}+h\right](1-\varepsilon)
\end{aligned}
$$

where $\phi$ represents the decreasing returns to public spending on basic education with regard to human capital accumulation. Consequently, the agent's maximizing problem is given by,

$$
\max _{h}\left\{\frac{\left[(1-h) \varphi \varepsilon^{\phi}(1-\varepsilon)\right]^{1-\theta}-1}{1-\theta}\right\}+\beta\left\{\frac{\left[\left(\varphi \varepsilon^{\phi}+h\right)(1-\varepsilon)\right]^{1-\theta}-1}{1-\theta}\right\}
$$

Solving this problem, we have as first order condition,

$$
\left[\frac{\left(\varphi \varepsilon^{\phi}+h\right)}{(1-h) \varphi \varepsilon^{\phi}}\right]^{\theta}=\frac{\beta}{\varphi \varepsilon^{\phi}}
$$

Thus, isolating $h$, we have that,

$$
h=\left\{\frac{\left[\left(\frac{\beta}{\varphi \varepsilon^{\phi}}\right)^{\frac{1}{\theta}}-1\right] \varphi \varepsilon^{\phi}}{\left(1+\left(\frac{\beta}{\varphi \varepsilon^{\phi}}\right)^{\frac{1}{\theta}} \varphi \varepsilon^{\phi}\right)}\right\}
$$

From this equation, we may then move on to the result put forth in proposition 5.

Proposition 5 The number of hours spent on the accumulation of human capital, $h$, is related to the amount of government spending on basic education, $\varepsilon$, although the sign of this relation may not be determined.

Proof: To prove this proposition, we must perform a sign analysis of $\partial h / \partial \varepsilon$ from equation (33), leading us to,

$$
\frac{\partial h}{\partial \varepsilon}=\frac{\left[\Omega-\varphi \phi \varepsilon^{\phi-1}\right][1+\Phi]-\Omega\left[\Phi-\varphi \varepsilon^{\phi}\right]}{[1+\Phi]^{2}}
$$

where,

$$
\left.\Omega=\frac{\phi \theta-\theta}{\theta} \beta^{\frac{1}{\theta}} \varphi^{\left(\frac{\theta-1}{\theta}\right)} \varepsilon_{\varepsilon} \frac{\phi \theta-\phi-\theta}{\theta}\right)
$$


and

$\Phi=\beta^{\frac{1}{\theta}} \varphi^{\frac{\theta-1}{\theta}} \varepsilon^{\frac{\phi \theta-\phi}{\theta}}$

The sign of this equation cannot be determined for any parameter value.

Proposition 5 indicates a result similar to that of proposition 2 making it clear that the existence of decreasing returns to government spending does not necessarily implicate changes in the model's results, but only in the value of the marginal effect of this relation.

\section{Government Spending on Basic Education and Growth}

From the models developed in the previous sections it was possible to observe the effects that government spending on basic education have on economic growth. In order to simplify our analysis, the population was held constant, i.e., the number of younger individuals is always equal to the number of older individuals. We then have that workers' average level of schooling is given by,

$$
\bar{H}=\frac{\varphi \varepsilon+(\varphi \varepsilon+h)}{2}
$$

for the model with linear government outlined in section 3, as well as the model with decreasing returns to human capital in the production function. For the model with decreasing returns to investment in human capital, this average is given by,

$$
\bar{H}=\frac{\varphi \varepsilon+\left(\varphi \varepsilon+h^{\gamma}\right)}{2}
$$

And for the model with decreasing returns to government spending on basic education, the average level of schooling of workers is given by,

$$
\bar{H}=\frac{\varphi \varepsilon^{\phi}+\left(\varphi \varepsilon^{\phi}+h\right)}{2}
$$

Thus, since the population held constant, we have that economic growth is proportional to the increase in the average level of schooling of workers. Therefore, from the above equations, it is possible to derive the rate of economic growth for each one of these four models, as follows, 


$$
\begin{gathered}
\frac{\dot{Y}}{Y}=\frac{\dot{\bar{H}}}{\bar{H}}=\frac{\left[\varphi+\frac{1}{2} \frac{d h}{d \varepsilon}\right]}{\left[\varphi \varepsilon+\frac{h}{2}\right]} \dot{\varepsilon} \\
\frac{\dot{Y}}{Y}=\alpha \frac{\dot{\bar{H}}}{\bar{H}}=\alpha\left\{\frac{\left[\varphi+\frac{1}{2} \frac{d h}{d \varepsilon}\right]}{\left[\varphi \varepsilon+\frac{h}{2}\right]} \dot{\varepsilon}\right\} \\
\frac{\dot{Y}}{Y}=\frac{\dot{\bar{H}}}{\bar{H}}=\left\{\frac{\left[\varphi+\frac{\gamma}{2} h^{\gamma-1} \frac{d h}{d \varepsilon}\right]}{\left[\varphi \varepsilon+\frac{h^{\gamma}}{2}\right]} \dot{\varepsilon}\right\} \\
\frac{\dot{Y}}{Y}=\frac{\dot{\bar{H}}}{\bar{H}}=\left\{\frac{\left[\varphi \phi \varepsilon^{\phi-1}+\frac{1}{2} \frac{d h}{d \varepsilon}\right]}{\left[\varphi \varepsilon^{\phi}+\frac{h}{2}\right]} \dot{\varepsilon}\right\}
\end{gathered}
$$

Where the above equations are the rates of economic growth of the models with government, listed according to the order in which the models appear in this study.

It is thus not possible to affirm, in any of the cases, that an increase in government spending on basic education would necessarily lead to an increase in the average number of years of schooling, and consequently, in production. In particular, when there are decreasing returns to the human capital stock or to human capital accumulation, considering the usual $\theta<1$ hypothesis, we have that the average level of schooling would increase less than government spending on education, possibly implicating a negative or hardly significant relation. In the other cases, as when the sign of $d h / d \varepsilon$ cannot be determined, this relation may assume high or non-significant values, depending on the model's parameter values.

The immediate conclusion of this study is that, since government spending on basic education may have a negative effect on agents' incentive to accumulate human capital via higher education, if the government allocates a higher value to basic education in detriment to higher education subsidies, these expenditures may be insignificant with regard to the human capital stock and economic growth. This conclusion explains the non-consensus with regard to the significance of this relation, explaining the stylized fact described in the introduction, where countries with high levels of government spending on basic education in detriment of higher education have lower per capita GNP levels with regard to the rest. It thus becomes clear that the composition of government spending between basic and higher education is important with regard to the significance of the relation between public spending on education and economic growth.

\section{Concluding Remarks}

This paper sought to investigate the relation between public spending on basic education and economic growth. As evidenced by the constructed models, this relation 
is not trivial, and there may be a drastic change in results according the theoretical specifications adopted.

In this paper, five complementary theoretical models were constructed. The first model is a simple private-choice human capital accumulation model, in which the agents' are endowed with an initial stock of human capital when entering the labor market. In this case, it becomes clear that agents tend to accumulate more human capital when they are endowed with a higher initial human capital stock. This result is important for it demonstrates that the human capital accumulated by agents during childhood affects the economic decisions made during their lives.

The second model proposed introduces government in the context, and observes how government spending on basic education interacts with the private decision to accumulate human capital. In this case, the sign of the relation between public spending on education and the private accumulation of human capital cannot be determined. This result arises from the fact that an increase in education spending, which increases agents' initial human capital stock via an increase in revenue collection, promotes and hinders human capital accumulation for different reasons.

The subsequent models proposed introduced different types of decreasing returns to the model with government: decreasing marginal returns to the human capital stock in the production function, to hours spent in accumulating human capital, and to public spending on basic education. In the model with decreasing returns to the human capital stock and its accumulation we concluded that an increase in government spending on basic education implicates a decline in private human capital investment, and in the model with decreasing returns to government spending the results are not substantially different.

From the results obtained, we may reach the central conclusion that basic education affects agents' decisions over their lifetime, and that the significance of the relation between public spending on education and economic growth is altered by changes in the composition of government spending with regard to basic and higher education, and this relation may be insignificant when higher education is not promoted.

\section{References}

[1] Barro, R., Sala-i-Martin, X., 1999. Economic Growth. MIT Press, Cambridge, MA.

[2] Blankeanu, W.F., 2003. Public schooling, college subsidies and growth. Forthcoming. Journal of Economic Dynamics and Control.

[3] Bouzahzah, M., De la Croix, D., Docquier, F., 2002. Policy Reforms and Growth in Computable OLG Economies. Journal of Dynamics and Control, 26, 2093-2113. 
[4] Brauninger, M., Vidal, J.P., 1999. Private versus public financing of education and endogenous growth. Journal of Population Economics 13, 387- 401.

[5] Cassou, S., Lansing, K., 2001. Tax reform and public sector investment in human capital. Manuscript.

[6] Cullison, W., 1993. Public investment and economic growth. Federal Reserve Bank of Richmond Economic Quarterly 79, 19- 33.

[7] Easterly, W., Rebelo, S., 1993. Fiscal policy and economic growth. Journal of Monetary Economics 32, 417- 458.

[8] Eckstein, Z., Zilcha, I., 1994. The effects of compulsory schooling on growth, income distribution and welfare. Journal of Public Economics 53, 339-359.

[9] Glomm, G., Ravikumar, B., 1992. Public versus private investment in human capital: endogenous growth and income inequality. Journal of Political Economy $100,818-834$.

[10] Glomm, G., Ravikumar, B., 1997. Productive government expenditures and long-run growth. Journal of Economic Dynamics and Control 21, 183-204.

[11] Glomm, G., Ravikumar, B., 1998. Flat-rate taxes, government spending on education, and growth. Review of Economic Dynamics 1, 306- 325.

[12] Hendricks, L., 1999. Taxation and long-run growth. Journal of Monetary Economics 43, $411-434$.

[13] Jones, C. I., 1995. RD based models of economic growth. Journal of Political Economy, v.103, n.4, p.759-784, august 1995.

[14] Kaganovich, M., Zilcha, I., 1999. Education, social security and growth. Journal of Public Economics 71, 289- 309.

[15] Levine, R., Renelt, D., 1992. A sensitivity analysis of cross-country growth regressions. American Economic Review 82, 942- 963.

[16] Lucas, R., 1988. On the Mechanics of Economic Development. Journal of Monetary Economics, 22, 3-42.

[17] Milesi-Ferretti, G., Roubini, N., 1998. On the taxation of human and physical capital in models of endogenous growth. Journal of Public Economics 70, 237254.

[18] Su, X., 2004. The allocation of public funds in a hierarchical educational system. Journal of Economic Dynamics Control. Forthcomming. 
[19] Zhang, J., 1996. Optimal public investment in education and endogenous growth. Scandinavian Journal of Economics 98, 387- 404.

[20] Zhang, J., Casagrande, R., 1998. Fertility, growth, and fat-rate taxation for education subsidies. Economics Letters 60, 209- 216. 